\title{
Gamificando as aulas de química: uma análise prospectiva das propostas de licenciandos em química
}

\author{
Bruno Silva Leite \\ Universidade Federal Rural de Pernambuco \\ leitebrunosilva@gmail.com
}

\begin{abstract}
Resumo: Com o objetivo de analisar as propostas de gamificar as aulas de química, este artigo relata os resultados de uma investigação realizada com setenta e nove (79) estudantes da licenciatura em química de uma universidade federal. Para contemplar o objetivo central da pesquisa, uma abordagem qualitativa, consideramos o estudo de caso em quatro etapas. Os resultados se estruturam apresentando as propostas e as percepções dos estudantes para gamificar as aulas de química, indicando contributos em sua aprendizagem e corroborando para uma aprendizagem ativa (centrada no aluno). Além disso, os estudantes realizaram uma experiência reflexiva que lhes permitiram identificar possibilidades para suas futuras práticas docentes.
\end{abstract}

Palavras-chave: Gamificação, Tecnologias no ensino, Ensino de Química.

\section{Gamification of chemistry classes: a prospective analysis of the proposals of chemistry graduates}

Abstract: With the aim of analyzing the proposals to gamify chemistry classes, this article reports the results of an investigation conducted with seventy-nine (79) undergraduate students in chemistry from a federal university. In order to contemplate the central objective of the research, a qualitative approach, we consider the case study in four steps. The results are structured by presenting the students' proposals and perceptions to gamify the chemistry classes, indicating contributions in their learning and corroborating to an active learning (student-centered). In addition, the students performed a reflective experience that allowed them to identify possibilities for their future teaching practices.

Keywords: Gamification, Technology in education, Chemistry Teaching.

\section{Introdução}

A utilização das tecnologias no ensino tem proporcionado boas mudanças no âmbito da educação. Nesse sentido, o impacto das Tecnologias Digitais da Informação e Comunicação (TDIC) em atividades relacionadas com o ensino e a aprendizagem nas instituições de ensino superior tem conduzido a ruptura de métodos e metodologias tradicionais de ensino que por sua vez estão "cristalizados" com o tempo (Leite, 2016). Embora não seja novidade, as metodologias ativas têm se destacado refletindo sobre o papel do professor e do aluno no processo de ensino e aprendizagem, buscando provocar mudanças nas práticas em sala de aula que estão, por muitas vezes, enraizadas no modelo tradicional de ensino.

As metodologias ativas possibilitam a valorização da formação crítica e reflexiva do estudante que participa da construção de seu conhecimento, no processo de ensino e aprendizagem, favorecendo sua autonomia. A proposta é que o aluno procure o conteúdo, pesquise e encontre soluções, aprendendo a refinar suas respostas. A diversidade de propostas que apresentam princípios norteados por metodologias ativas é bastante significativa na educação, tais como: sala de aula invertida, aprendizagem baseada em problemas, aprendizagem baseada em projetos, método de caso, avaliação por pares, peer instruction, design thinking, aprendizagem baseada em games e gamificação. Em relação 
a gamificação, a literatura (Klock, et al., 2014; Costa; Verdeaux, 2016; Araújo, 2016; Santos; Freitas, 2017) tem exposto alguns resultados significativos desta metodologia ativa aplicada ao ensino. Sabendo-se da grande popularidade e impacto que os games têm, independente do seu gênero, por que não utilizar seus elementos em favor do aprendizado? Nesta pesquisa, apresentamos algumas propostas de discentes do curso de licenciatura em química, de uma universidade federal, para gamificar suas aulas de forma que a incorporação dos elementos presente nos games (gamificação) venha a contribuir no processo de ensino e aprendizagem. Ao mesmo tempo, esperamos suscitar alguma luz sobre os pressupostos que cercam essa temática de maneira a contribuir para futuras discussões.

\section{Gamificação}

Partindo do pressuposto que as metodologias ativas não são novidades, a gamificação também pode seguir esse pensamento de não ser uma novidade. $\mathrm{O}$ que atualmente chamamos de gamificação, Brougère $(1998 ; 2002)$ chamava, há um bom tempo, de jogo educativo. Neste trabalho, assumimos os termos "game" e "jogo" como similares, uma vez que game é traduzido para o português como jogo e significa um tipo de jogo com regra, diferente da palavra Play, que também é um jogo, mas no sentido de diversão, prazer, lúdico, não necessariamente regrado. Além disso, o termo jogo digital (por vezes associado a game) nada mais é que um jogo aplicado em uma plataforma digital. Soares (2013) já alertava que definir jogo é difícil, talvez por isso com o surgimento do termo gamificação, algumas definições equivocadas emergiram, tais como: a origem da expressão ser provinda do acrônimo das palavras "Game" e "Educação" (Game + Education); como sendo o ato de utilizar games em ambientes educacionais, contudo tal ação compete a aprendizagem baseada em games (também fundamentada na metodologia ativa); a ação de aprender a partir dos games. Embora a gamificação tenha recebido críticas por aqueles que estudam jogos (Nicholson, 2012), observamos um crescimento exponencial de trabalhos envolvendo a gamificação na educação (Araújo, 2016; Costa; Verdeaux, 2016; Santos; Freitas, 2017).

Com o intuito de motivar, engajar e fidelizar clientes e usuários, a gamificação foi aplicada, inicialmente, em programas de marketing e aplicações para web (Zichermann; Cunningham, 2011). Na literatura encontramos algumas definições para gamificação, como: "o uso de elementos de design de games em contextos que não são de games" (Deterding, et al., 2011, p. 10), "a aplicação de mecânicas de games a atividades de que não de games" (Sheldon, 2012, p. 75) e que "compreende a aplicação de elementos de jogos em atividades de não jogos" (Leite, 2015, p. 348). Ela consiste na utilização de elementos dos games (pensamentos, mecânicas e estratégias) fora do contexto dos games, com o objetivo de motivar os indivíduos à ação, auxiliando a resolver problemas e promovendo aprendizagens (Kapp, 2012) ou se apropriar dos elementos comuns (motivação, interação, colaboração, pensamento crítico, enfrentar desafios) que aparecem no design de um game e estrategicamente utilizá-los para a aprendizagem (Leite, 2015). Podemos dizer que a gamificação busca motivar a participação, o engajamento e a fidelidade. Kapp, Blair e Mesch (2014) distinguem dois tipos de gamificação: 1) a estrutural que corresponde à aplicação de mecanismos de jogo ao conteúdo já existente; 2) a de conteúdo em que a informação, a dinâmica e o conteúdo em si são alterados através de métodos de design de jogos.

Em uma atividade gamificada, pelo menos um dos três elementos dos games (dinâmicas, mecânicas e componentes) devem estar presente. A Tabela 1 apresenta um resumo dos três elementos e suas principais características. 
Tabela 1 - Elementos dos Games.

\begin{tabular}{|c|c|c|}
\hline Dinâmicas & Mecânicas & Componentes (técnicas) \\
\hline Emoções & Aquisição de recursos & Avatar \\
\hline Narrativa & Avaliação (Feedback) & Bens virtuais \\
\hline Progressão & Chance & Boss \\
\hline Relacionamentos & Cooperação e competição & Coleções \\
\hline \multirow[t]{15}{*}{ Restrições } & Desafios & Combate \\
\hline & Recompensas & Conquistas \\
\hline & Transações & Conteúdos desbloqueáveis \\
\hline & Turnos & Emblemas/medalhas \\
\hline & Vitória & Gráfico Social \\
\hline & & Missão \\
\hline & & Níveis \\
\hline & & Pontos \\
\hline & & Presentes \\
\hline & & Ranking \\
\hline & & Times \\
\hline & & Integração \\
\hline & & Loops de engajamentos \\
\hline & & Regras \\
\hline & & Narrativa \\
\hline
\end{tabular}

Fonte: Adaptado de Klock, et al. (2014); Costa e Marchiori (2016).

Quando se fala em gamificar a aprendizagem, busca-se incorporar elementos presentes nos jogos em uma dinâmica na sala de aula, com a participação ativa do aluno, proporcionando o desenvolvimento de determinadas habilidades e comportamento. A educação gamificada tem como objetivo incentivar os alunos a aprenderem se divertindo, isto é, a gamificação desperta o interesse dos educandos, aumentando sua vontade de aprender. Ademais, a gamificação na educação possibilita: a) Feedback instantâneo; b) $\mathrm{O}$ aumento do comprometimento com a aprendizagem; c) Maior controle sobre a aprendizagem; d) Oportunidades para a resolução de problemas de forma colaborativa; e) Refazer mais de uma vez a mesma tarefa quando o aluno erra, pois ele pode tentar de novo sem consequências negativas provindas do professor ou dos colegas.

É comum ouvirmos afirmações dos estudantes considerando que as aulas não são atraentes e por isso não se envolvem com elas e, consequentemente, não aprendem direito. Nesse sentido, gamificar a aula pode ser importante para o processo de ensino e aprendizagem. Isso não significa que o professor deve gamificar todas as aulas, há questões que devem ser analisadas antes de se decidir pela abordagem, porém sua incorporação por meio de estratégias se torna um recurso extremamente valioso para que a aprendizagem seja centrada no aluno, ou seja, que o aluno seja ativo durante todo o processo de construção do conhecimento. Cabe ressaltar que, a gamificação na educação é apropriada quando se pretende: 1) Motivar alunos a aprenderem os conteúdos disciplinares; 2) Influenciar o comportamento do aluno em sala de aula; 3) Guiar os alunos para que possam inovar na resolução dos problemas propostos; 4) Encorajar nos alunos a autonomia para desenvolver competências e habilidades; 5) Ensinar novos conteúdos.

\section{Materiais e métodos}

A pesquisa de natureza qualitativa (Lüdke; André, 2012) abrange uma abordagem descritiva e interpretativa das propostas de gamificação pelos sujeitos investigados. A partir de um estudo de caso, em que um acontecimento específico (ou contexto) é pesquisado detalhadamente, busca-se avaliar descritivamente as propostas apresentadas. Nesse sentido, a pesquisa foi desenvolvida em quatro etapas. (i) Discussões sobre 
Gamificação com os estudantes. Neste momento, foram debatidos atributos da gamificação na educação e como esta pode contribuir no processo de ensino e aprendizagem; (ii) Levantamento sobre a gamificação na Química. Nesta etapa, os estudantes realizaram um levantamento de artigos/teses/dissertações em periódicos que envolvessem a gamificação no ensino de química, para utilizarem como material de consulta na elaboração de suas propostas e posteriormente entregaram ao professor da disciplina a relação dos trabalhos encontrados; (iii) Elaboração de propostas para atividades gamificadas no Ensino de Química. Neste momento, os estudantes realizaram a proposição de atividades baseadas no conceito da gamificação. Cabe destacar que o estilo de atividade elaborada e os conteúdos envolvidos na proposta foi de escolha livre pelos estudantes. Estes ainda entregaram um resumo de suas propostas; (iv) Os estudantes apresentaram um seminário explicitando os objetivos da proposta de aula gamificada no Ensino de Química, justificando o uso das imagens e textos, além de destacarem como os conceitos químicos seriam introduzidos em sua futura prática docente. Este momento foi gravado em áudio utilizando um smartphone. O tempo máximo para apresentação do seminário foi de dez (10) minutos, devido ao cronograma das disciplinas. Ainda neste momento, o professor realizou intervenções sobre as propostas produzidas.

Os seminários ocorreram com a presença do pesquisador que se baseou na "escuta sensível" proposta por Barbier (2002). Resumidamente, a escuta sensível pretende compreender o sentido que existe em uma situação (pode ser uma prática), segundo uma abordagem rogeriana. Como consequência, o pesquisador deve "saber sentir o universo afetivo, imaginário e cognitivo do outro para poder compreender de dentro suas atitudes, comportamentos e sistema de ideias, de valores de símbolos e de mitos" (Barbier, 2002, p. 1). Após a transcrição das falas, foram analisadas interlocuções dos sujeitos, quanto à potencialidade das propostas em contribuir para uma aula gamificada.

Neste artigo a unidade de análise da pesquisa é composta por setenta e nove (79) estudantes do curso de licenciatura em química de uma universidade federal em Pernambuco, sendo quarenta e cinco (45) da disciplina Informática, Química e Educação (IQE) dividido em duas turmas, vinte e um (21) do semestre 2016.2 e vinte e quatro (24) do semestre 2017.1 e trinta e quatro (34) da disciplina Instrumentação para o Ensino de Química (IEQ), dezoito (18) estudantes do semestre 2016.2 e dezesseis (16) do semestre 2017.1. Para garantir o anonimato dos participantes, retirou-se dados que poderiam identificar os sujeitos. Nesse contexto, usamos $E_{N}$ para representar a fala do discente, em que $\mathrm{N}=1,2,3, \ldots 79$. Os estudantes da disciplina IQE foram numerados de $\mathrm{E}_{1}$ até $\mathrm{E}_{45} \mathrm{e}$ os da disciplina IEQ de $\mathrm{E}_{46}$ a $\mathrm{E}_{79}$.

\section{Resultados obtidos}

Na presente seção, apresentamos os resultados alcançados durante o processo de investigação da pesquisa. Primeiramente os resultados do levantamento dos estudantes sobre a gamificação na literatura (etapa 2), destacando-se um breve resumo sobre a pesquisa, em seguida a análise das propostas para gamificar as aulas de química (etapa 3), relacionando com algumas percepções dos estudantes obtidas durante os seminários (etapa 4). As discussões relativas a Gamificação (etapa 1) foram realizadas durante as aulas das disciplinas envolvidas, na forma de aula expositiva dialógica.

\subsection{Levantamento e análise da Gamificação no Ensino de Química}

Após as discussões da etapa 1 foi realizado o levantamento pelos estudantes de trabalhos sobre a gamificação na química (etapa 2), que entregaram ao professor responsável por cada disciplina informações sobre o material pesquisado (se era um artigo, tese ou dissertação, ano e local da publicação e o link para o texto). Diante desses 
dados, realizamos uma breve análise em relação aos materiais selecionados pelos estudantes. Ao todo foram indicados 4 artigos, 2 dissertações e nenhuma tese (Tabela 2), alguns trabalhos foram selecionados por mais de um estudante. É preciso destacar que alguns textos selecionados pelos estudantes se tratavam de resumos e/ou anais de eventos científicos, sendo desconsiderados nesta análise. Os ambientes de busca foram restritos espontaneamente pelos estudantes nas plataformas: Google Acadêmico (4 artigos e 1 dissertação), Periódico CAPES (nenhum artigo), Banco de Teses e Dissertações (nenhum artigo), Biblioteca Digital Brasileira de Teses e Dissertações (1 dissertação) e Scielo (nenhum artigo). Observamos que nesses ambientes de busca há trabalhos envolvendo a gamificação na física, matemática, pedagogia, biologia, português, história, entre outras áreas, contudo, na química o número de trabalhos é praticamente ínfimo.

Tabela 2 - Gamificação na Química.

\begin{tabular}{|c|c|c|c|c|}
\hline Tipo & Nome & Autores & Ano & Publicado em \\
\hline Artigo & $\begin{array}{c}\text { Ambiente de Ensino de Química } \\
\text { Orgânica Baseado em } \\
\text { Gamificação }\end{array}$ & $\begin{array}{l}\text { Fernandes, } \\
\text { A.M.R.; } \\
\text { Castro, F.S. }\end{array}$ & 2013 & $\begin{array}{c}\text { Revista de Exatas e } \\
\text { TECnológicas, v. 4, n. 2, p. } \\
\text { 24-34, 2013. }\end{array}$ \\
\hline Artigo & $\begin{array}{l}\text { Gamificación y la Física- } \\
\text { Química de Secundaria }\end{array}$ & Pérez, F. Q. & 2016 & $\begin{array}{l}\text { Education in the Knowledge } \\
\text { Society, v. } 17, \text { n. } 3 \text {, p. 13-28, } \\
2016 .\end{array}$ \\
\hline Artigo & $\begin{array}{c}\text { Mapas Conceituais e Storyboard } \\
\text { como Metodologia para a } \\
\text { Produção de Aplicativo } \\
\text { Gamificado para o Ensino de } \\
\text { Ciências }\end{array}$ & Américo, M. & 2016 & $\begin{array}{l}\text { Revista de estudios para el } \\
\text { desarrollo social de la } \\
\text { comunicación, n. 14, p. 28- } \\
47,2016 .\end{array}$ \\
\hline Artigo & $\begin{array}{l}\text { Aplicación de herramientas de } \\
\text { gamificación en física y química } \\
\text { de secundaria }\end{array}$ & Pérez, F. Q. & 2016 & $\begin{array}{c}\text { Opción, Año 32, Especial, n. } \\
\text { 12, p. 327-348, } 2016 .\end{array}$ \\
\hline $\begin{array}{l}\text { Disser- } \\
\text { tação }\end{array}$ & $\begin{array}{l}\text { Os efeitos do Game Design no } \\
\text { processo de criação de jogos } \\
\text { digitais utilizados no ensino de } \\
\text { Química e Ciências: o que } \\
\text { devemos considerar? }\end{array}$ & $\begin{array}{l}\text { Guerreiro, } \\
\text { M.A.S. }\end{array}$ & 2015 & $\begin{array}{c}\text { Universidade Estadual } \\
\text { Paulista Julio de Mesquita } \\
\text { Filho, Pós-Graduação em } \\
\text { Educação para a Ciência, } \\
297 \text { f. }\end{array}$ \\
\hline $\begin{array}{l}\text { Disser- } \\
\text { tação }\end{array}$ & $\begin{array}{c}\text { Laboratório virtual gamificado } \\
\text { para a prática experimental no } \\
\text { ensino de química }\end{array}$ & $\begin{array}{l}\text { Pereira, } \\
\text { S.R.C. }\end{array}$ & 2015 & $\begin{array}{l}\text { Universidade Federal do } \\
\text { ABC, Programa de Pós- } \\
\text { Graduação em Engenharia } \\
\text { da Informação, } 153 \mathrm{f.}\end{array}$ \\
\hline
\end{tabular}

Fonte: Extraído da pesquisa dos estudantes.

O número limitado de publicações encontradas pelos estudantes demonstram a necessidade de mais pesquisas envolvendo a gamificação no ensino de química. Os trabalhos identificados na Tabela 2 exploram os elementos presentes nos games, tais como ranking, recompensa, desafios entre outros.

\subsection{Propostas e percepções dos estudantes para gamificar as aulas de química}

Apresentamos as propostas dos estudantes referentes à gamificação de uma aula de química (etapa 3). Para melhor discussão das propostas, agregamos nesta seção algumas falas dos estudantes durante os seminários (etapa 4), na qual expressavam suas percepções quanto a aplicação e importância das propostas. Para a elaboração da atividade foram formados grupos com no mínimo quatro (04) e no máximo seis (06) estudantes, totalizando dezessete (17) propostas de atividade gamificada. Os nomes das propostas apresentadas pelos estudantes estão descritas na Tabela 3, para facilitar a fluidez da leitura nomeamos cada proposta por $\mathrm{P}_{\mathrm{N}}(\mathrm{N}=$ número da proposta). Ressaltamos algumas propostas e percepções, que em nosso modo de ver, resultam ser mais interessantes para 
as discussões, considerando que destacar todas as propostas e opiniões não é necessário neste momento.

Tabela 3 - Propostas dos estudantes para gamificar a aula de Química.

\begin{tabular}{|c|c|c|c|}
\hline Proposta & Título da atividade gamificada & Turma & $\mathbf{N}^{\mathbf{0}}$ de estudantes \\
\hline 1 & Tabela periódica dos alimentos & IQE 2016.2 & 5 \\
\hline 2 & Jogo de Reconhecimento & IQE 2016.2 & 5 \\
\hline 3 & Propriedades periódicas & IQE 2016.2 & 5 \\
\hline 4 & Tabela periódica & IQE 2016.2 & 6 \\
\hline 5 & Laboratório virtual & IQE 2017.1 & 5 \\
\hline 6 & Modelos atômicos & IQE 2017.1 & 5 \\
\hline 7 & Substâncias químicas & IQE 2017.1 & 5 \\
\hline 8 & Estrutura da matéria & IQE 2017.1 & 5 \\
\hline 9 & Modelo de Rutherford & IQE 2017.1 & 4 \\
\hline 10 & Gamificação em Química Orgânica 1 & IEQ 2016.2 & 5 \\
\hline 11 & Materiais e processos de separação & IEQ 2016.2 & 5 \\
\hline 12 & Conhecendo a tabela periódica & IEQ 2016.2 & 4 \\
\hline 13 & Equilibrando a química & IEQ 2016.2 & 4 \\
\hline 14 & Solucionando a química & IEQ 2017.1 & 4 \\
\hline 15 & Velocidade das reações & IEQ 2017.1 & 4 \\
\hline 16 & Proteínas e propriedades químicas dos aminoácidos & IEQ 2017.1 & 4 \\
\hline 17 & A química por trás do petróleo & IEQ 2017.1 & 4 \\
\hline
\end{tabular}

Fonte: Dados da pesquisa.

Para análise dessas propostas realizou-se a seleção de uma atividade por turma, tendo como critério de escolha as propostas com maior número de elementos dos games em cada turma, a saber: $\mathrm{P}_{1}, \mathrm{P}_{5}, \mathrm{P}_{10}$ e $\mathrm{P}_{16}$. A Figura 1 apresenta as imagens das propostas $\left(\mathrm{P}_{1}, \mathrm{P}_{5}, \mathrm{P}_{10}\right.$ e $\left.\mathrm{P}_{16}\right)$ extraídas das apresentações dos grupos. Além disso, cabe ressaltar que para facilitar a leitura, ao utilizarmos a palavra alunos (nas linhas que se seguem) nos referimos àqueles (público alvo) que o professor irá utilizar a proposta em sala de aula e o termo estudantes, referimo-nos aos estudantes da licenciatura que propuseram a atividade gamificada, em outras palavras, alunos são aqueles que irão realizar a atividade e estudante aqueles que propuseram a atividade.
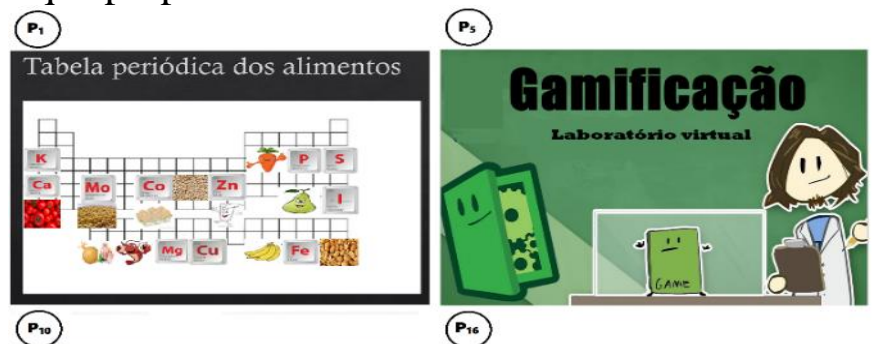

Introdução a Química
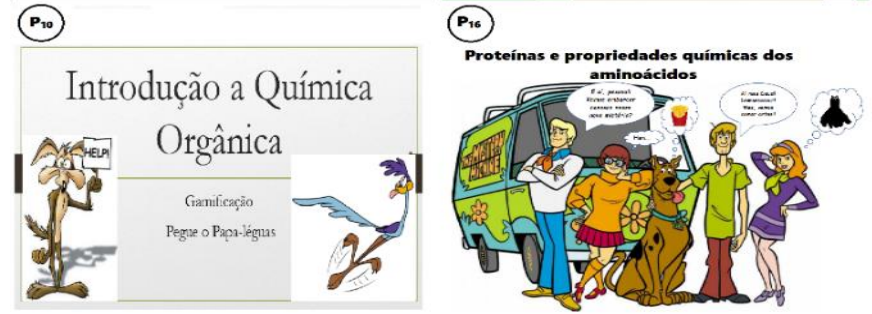

Figura 1 - Propostas das atividades gamificadas apresentadas nos seminários.

Em relação a $\mathrm{P}_{1}$, seu objetivo era utilizar os elementos da tabela periódica associando-a com os alimentos. A proposta foi dividida em quatro missões. No seminário $\mathrm{E}_{2}$ destaca que uma das propostas era "fazer com que o aluno usasse o jogo da memória com o nome de alguns elementos da tabela periódica, fazendo com que o aluno soubesse onde esses elementos podem ser encontrados e em quais alimentos". Segundo E1, 
"pensamos em colocar o jogo da forca como um desafio para os alunos que teriam dicas para desvendar qual elemento químico está relacionado com o alimento". Já para $\mathrm{E}_{5} \mathrm{o}$ uso de cartões com os elementos químicos (um jogo de cartas) deve "ajudar os alunos a reconhecerem alguns elementos através de suas propriedades físico-química, a posição dos elementos na tabela e as aplicações nos alimentos". Durante o seminário as falas dos estudantes expõem o foco do grupo em utilizar os elementos dos games na perspectiva de desafiar e motivar os alunos a realizarem as atividades, que Costa e Verdeaux (2016) ressaltam a importância em se utilizar conteúdos atrativos, pois contribuem para uma boa atividade gamificada.

$\mathrm{Na}$ análise da $\mathrm{P}_{5}$ observamos que este grupo enfatizou a atividade gamificada direcionada ao uso do laboratório. A proposta da atividade busca ambientar o aluno "como se estivesse no laboratório" ( $\left.E_{26}\right)$, desafiando-o "a compreender a dinâmica e a rotina de um laboratório de química" $\left(\mathrm{E}_{22}\right)$. A atividade apresenta cinco fases que são descritas durante uma narrativa. O aluno "vira" um jovem cientista (usando um avatar) que caminha pelo laboratório, sendo desafiado em todas as fases por outro cientista ("Einstein") a resolver problemas envolvendo as vidrarias, soluções e equipamentos que estão dentro do laboratório. Durante a apresentação do seminário $E_{24}$ reforçou que "os alunos vão ter que usar o caça palavras e a forca para resolverem as charadas de Einstein" e $E_{26}$ complementa que "o desafio do aluno é resolver o problema proposto com os conhecimentos que ele tem sobre reação química". A situação relatada durante o seminário demonstrou a inserção da resolução de problemas na proposta de gamificar as aulas de química pelos estudantes, possibilitando a promoção da aprendizagem dos envolvidos (Kapp, 2012; Leite, 2015; Araújo, 2016; Santos; Freitas, 2017), tendo a aprendizagem ativa do aluno como um princípio fundamental.

A $\mathrm{P}_{10}$ propõe uma gamificação para compreender os conteúdos da química orgânica de forma que minimize as dificuldades dos alunos neste conteúdo. A proposta foi dividida em cinco missões e utilizou dois personagens de desenhos animados (Papaléguas e Coiote) para auxiliar na gamificação da proposta. A narrativa presente na $\mathrm{P}_{10}$ a torna engajadora, ao tempo que utiliza o desenho como fonte motivadora para atividade e atribui desafios e pontuações para resolver os problemas (Araújo, 2016; Santos; Freitas, 2017). Em relação aos personagens envolvidos, durante o seminário $E_{50}$ destaca que "achei legal as falas para motivar o coiote a pegar o Papa-léguas, principalmente quando usava a química para ajudar na ação". Ainda durante o seminário, E 47 destaca que "a briga entre o Papa-léguas e o coiote é conhecido por muitos alunos, então eles vão se envolver com a proposta" e E50 completa que "como é um desafio para o coiote pegar o Papaléguas, os alunos vão se sentir desafiados para resolverem a atividade", corroborando com as ideias de Araújo (2016) e Costa e Verdeaux (2016) sobre a importância das atividades serem engajadoras, na qual o aluno deve se sentir motivado para realizar uma tarefa.

Em relação as dificuldades apresentadas na elaboração da proposta, $\mathrm{E}_{48}$ considera que o tempo é um fator importante, nas palavras dele "se tiver tempo dá pra fazer uma gamificação muito boa", já E50 pondera que "o professor já é atarefado, como [ele] vai fazer uma proposta dessa se não tem tempo nem de preparar uma aula?’. Nesse momento, um dos estudantes relata que " $[\mathrm{Eu}]$ senti muita dificuldade em pensar em uma proposta gamificada, pois dentro de mim tudo era jogo" $\left(\mathrm{E}_{14}\right)$. A fala deste estudante remete à dificuldade na compreensão da gamificação (usar elementos dos games em ambientes que não são games), entretanto, $\mathrm{E}_{8}$ interviu na fala e mencionou que "a ideia é de um jogo, mas [você] não precisa fazer um jogo. Só porque tem motivação é um jogo? A gente tem que pensar assim: para ser motivador tem que ser um jogo? Não. Podemos fazer atividades motivadoras sem precisar fazer um jogo". Araújo (2016) destaca que um dos objetivos da gamificação em questões pertinentes a educação é gerar a motivação. 
Finalmente, a $\mathrm{P}_{16}$ apresenta uma atividade gamificada baseada nos conteúdos sobre proteínas e propriedades químicas dos aminoácidos, partindo do pressuposto que os alunos já haviam estudado sobre o assunto. A proposta apresenta uma característica interdisciplinar por envolver conceitos da biologia e da química, tendo como objetivo abordar o assunto de proteínas de uma forma mais integrada, interativa, contextualizada sobre as funções das proteínas, destacando as propriedades químicas que caracterizam os aminoácidos, tais como, funções orgânicas e polaridade. Além disso, a proposta fez uso dos personagens do desenho animado Scooby-Doo. Ao todo foram cinco missões com, pelo menos, um elemento dos games presente. Cada missão apresentava um título na qual o desafio era destacado. A atividade inicia com uma narrativa criada a partir de um contexto sobre alimentação, contendo regras instrutivas que vão direcionando os desafios que deverão ser superados pelos estudantes.

Durante o seminário o grupo explicitou a proposta, destacando que "a primeira missão tem por objetivo fazer com que o aluno entenda a importância das proteínas para uma boa nutrição alimentar" (E $\left.\mathrm{E}_{74}\right)$ e que após passar desta missão a segunda "busca levar o jogador a demonstrar seus conhecimentos acerca de funções orgânicas, de forma que ele consiga identificar a função presente em cada cadeia lateral de cada um dos aminoácidos" ( $\left.E_{75}\right)$. Já $E_{72}$ destaca que "o legal dessa gamificação é que o aluno tem que resolver os desafios e um deles leva o [personagem do] Salsicha a ajudar o Scooby a ganhar um biscoito", caracterizando como um sistema de recompensa. É importante destacar que as recompensas são um dos principais componentes de uma atividade gamificada, pois valida o esforço do aluno e reconhece o triunfo alcançado na resolução de um desafio (Costa; Verdaux, 2016).

Os dados obtidos nas discussões dos seminários possibilitaram compreender os motivos que levaram os grupos a inserirem os elementos dos games nas propostas de gamificação. Observamos também que vários elementos dos games (Tabela 1) estavam presentes nas missões. Ademais, na explicação de uma das missões da $\mathrm{P}_{5}, \mathrm{E}_{23}$ afirma que "no sistema de pontuação, cada nível concluído com sucesso, tinha uma pontuação alcançada, de forma que incentiva o jogador a continuar na interação, neste ponto, [eu] acho que já se torna claro o surgimento do Flow". O conceito de Flow (Csikszentmihalyi, 2008) foi criado a partir da definição do estado em que as pessoas se envolvem em determinadas atividades a ponto de nada mais ao seu redor apresentar importância, pois a própria experiência proporciona prazer e uma sensação agradável de felicidade. Algumas características que se fazem presentes quando a pessoa está em Flow: Foco e concentração; Êxtase; Clareza/Feedback; Habilidades; Crescimento; Perda da sensação do tempo; Motivação intrínseca. Outro aspecto relevante desta pesquisa é o fato do quiz ter sido um dos recursos mais utilizados nas propostas dos estudantes, na qual das 17 propostas 14 continham o quiz. Este pode ser utilizado como um recurso para envolver os estudantes e estimular o interesse por temas específicos (Leite, 2015).

Com base nas propostas e discussões nos seminários, observamos que o nível de profundidade das propostas de aula gamificada entre as turmas foram distintas. Os grupos da disciplina IQE apresentaram atividades relacionadas a vários jogos, suscitando suas dificuldades em utilizar elementos dos games em ambientes que não são games, o que nos grupos de IEQ ocorreu de forma pouco expressiva. Consideramos que este fato pode estar relacionado com o período que estes estudantes encontravam-se na sua formação como futuros professores de química no curso de licenciatura (química). A disciplina de IQE é ofertada no primeiro ano da graduação (segundo período), enquanto a disciplina de IEQ é ofertada no quarto ano do curso (sétimo período). Nesse sentido, os estudantes de IEQ perpassaram por diversas disciplinas, quer pedagógicas ou específicas de formação, possibilitando um arcabouço de estratégias para a proposição da atividade gamificada no 
ensino de química. Com base nessa informação, consideramos que a proposição de atividades gamificadas por estudantes da licenciatura deva ocorrer em disciplinas que estão próximas da formação dos mesmos (disciplinas que estão nos últimos anos do curso, por exemplo), pois as possibilidades deles utilizarem mais elementos dos games, em ambientes que não são games, é maior e consequentemente propondo com mais profundidade teórica a atividade gamificada.

Entre os estudantes, há também o discurso de que a compreensão do processo de gamificação nas aulas de química, sugere uma mudança nas práticas de ensino baseada no ensino transmissivo, como relata $E_{12}$ "são várias possibilidades de trabalhar conteúdos químicos com a gamificação, saindo da aula tradicional".

Por fim, cabe ressaltar que gamificar as aulas de química pode ser uma metodologia favorável no processo de ensino e aprendizagem, principalmente quando a aprendizagem está centrada no aluno. Consideramos que é importante discutir o quanto a gamificação pode contribuir em relação ao conhecimento científico na formação do aluno e que o conhecimento adquirido durante uma atividade gamificada contribua para romper com as práticas tradicionais, por muitas vezes enraizadas nas aulas de química.

\section{Considerações finais}

Este estudo procurou apresentar propostas para gamificar as aulas de química por discentes do curso de licenciatura em química. A análise das propostas e as percepções dos estudantes sobre a gamificação no ensino de química mostraram, por um lado, que embora seja necessário tempo e dedicação para sua elaboração, as atividades gamificadas apresentam contributos na aprendizagem do aluno e, por outro, são suscetíveis a aprendizagem ativa (centrada no aluno). Conforme descrito por Costa e Verdeaux (2016, p. 78), a prática da gamificação em sala de aula "provoca os professores a buscarem temas dentro do cotidiano de seus estudantes a fim de elaborar aulas mais dinâmicas e que permitam uma real compreensão dos conteúdos ensinados”. Nesse contexto, acreditamos que a gamificação pode contribuir na construção do conhecimento dos estudantes envolvidos.

Do ponto de vista dos licenciandos, a proposta de gamificar as aulas de química, foi uma experiência reflexiva que lhes permitiram identificar possibilidades para suas futuras práticas docentes. Eles também destacaram que o tempo seria um dos maiores desafios que poderiam encontrar como futuros professores na implementação da gamificação como uma estratégia de ensino e aprendizagem.

A gamificação considerada por muitos como algo inevitável e que iria revolucionar o mundo principalmente devido ao desenvolvimento tecnológico (Schell, 2010), encontra-se ainda em uma fase pré-embrionária no ensino superior e básico, principalmente no ensino de química. É de se esperar que os cursos de formação desenvolvam estratégias baseadas em metodologias ativas a fim de responder as necessidades dos docentes e estudantes. Nesse contexto, a gamificação pode contribuir para o processo de ensino e aprendizagem. É preciso destacar que a mera aplicação de mecanismos do jogo em qualquer contexto não significa que se atinja o efeito desejado em uma proposta de gamificar a sala de aula. Ademais, nossa prospecção é de que o êxito da gamificação na educação dependa da utilização planejada pelo professor, que seja capaz de engajar seus alunos, e que estes possam identificar os objetivos da atividade proposta, superando os desafios que esta metodologia impõe, por exemplo, uma demanda de tempo superior de quando o professor prepara outras atividades.

Por fim, cabe ressaltar que gamificar as aulas de química de maneira constante, não é aconselhado. A ideia é que o uso de atividades gamificadas, como de qualquer outra atividade, ocorra por meio de estratégias, se adequando as necessidades e capacidade real 
de cada situação de aula, assim possibilitando uma mudança na prática pedagógica, no intuito de contribuir na construção do conhecimento de forma mais flexível e dinâmica de todos os envolvidos.

\section{Referências}

ARAÚJO, I. Gamification: metodologia para envolver e motivar alunos no processo de aprendizagem. Teoría de la Educación. Educación y Cultura en la Sociedad de la Información, v. 17, n. 1, p. 87-107, 2016.

BARBIER, R. Escuta sensível na formação de profissionais de saúde. Conferência na Escola Superior de Ciências da Saúde. Brasília, 2002. Disponível em: <http://www.barbier-rd.nom.fr/ESCUTASENSIVEL.PDF>. Acesso: 20 set. 2017.

BROUGÈRE, G. Jogo e Educação. Porto Alegre: Artes Médicas, 1998.

BROUGÈRE, G. Lúdico e Educação: novas perspectivas. Linhas Críticas, v.8, n.14, p. 5-20, 2002.

COSTA, A. C. S.; MARCHIORI, P. Z. Gamificação, elementos de jogos e estratégia: uma matriz de referência. InCID: Revista de Ciência da Informação e Documentação, v. 6, n. 2, p. 44-65, 2015.

COSTA, T. M.; VERDEAUX, M. F. S. Gamificação de materiais didáticos: uma proposta para a aprendizagem significativa da modelagem de problemas físicos. Experiências em Ensino de Ciências, v.11, n. 2, p. 60-105, 2016.

CSIKSZENTMIHALYI, M. Flow: the psychology of optimal experience. New York: Harper Perennial, 2008.

DETERDING, S.; DIXON, D.; KHALED, R.; NACKE, L. From game design elements to gamefulness: defining gamification. In: Proceedings of the 15th international academic MindTrek conference: Envisioning future media environments. ACM, p. 9-15, 2011.

KAPP, K. M. The Gamification of Learning and Instruction: Game-basedMethods and Strategies for Training and Education. San Francisco: Pfeiffer, 2012.

KAPP, K. M.; BLAIR, L.; MESCH, R. The Gamification of Learning and instruction Fieldbook: Ideas into Practice. EUA: Wiley, 2014.

KLOCK, A. C. T.; CARVALHO, M. F.; ROSA, B. E.; GASPARINI, I. Análise das técnicas de Gamificação em Ambientes Virtuais de Aprendizagem. RENOTE, v. 12, n. $2,2014$.

LEITE, B. S. Aprendizagem tangencial no processo de ensino e aprendizagem de conceitos científicos: um estudo de caso. RENOTE, v.14, n.2, p. 1-10, 2016.

LEITE, B. S. Tecnologias no ensino de química: teoria de prática na formação docente. Curitiba: Appris, 2015.

LUDKE, M.; ANDRÉ, M. E. D. A. Pesquisa em Educação: Abordagens qualitativas. São Paulo: E.P.U., 2012.

NICHOLSON, S. A user-centered theoretical framework for meaningful gamification. Games+ Learning+ Society, v. 8, n. 1, p. 223-230, 2012.

SANTOS, J. A.; FREITAS, A. L. C. Gamificação Aplicada a Educação: Um Mapeamento Sistemático da Literatura. RENOTE, v. 15, n. 1, 2017.

SCHELL, J. Design Outside the Box. 2010. Disponível em: https://goo.gl/3Qv1Yu. SHELDON, L. The multiplayer classroom: designing coursework as a game. Boston, MA: Course Technology, Cengage Learning, 2012.

SOARES, M. H. F. B. Jogos e Atividades Lúdicas para o Ensino de Química. Goiânia: Kelps, 2013.

ZICHERMANN, G.; CUNNINGHAM, C. Gamification by Design. Implementing Game Mechanics in Web and Mobile Apps. Canada: O’ReillyMedia, 2011. 